\title{
Correlation of Trainees' Selection Scores with their Subsequent Performance during Specialty Training in Anesthesiology
}

\author{
Aliya Ahmed ${ }^{1}$ and Rashida Ahmed²
}

\begin{abstract}
Objective: To determine the correlation of trainee selection scores (TSS) with subsequent performance in anesthesiology trainees at a university hospital.

Study Design: Descriptive analytical study.

Place and Duration of Study: The Aga Khan University Hospital, Karachi, from August 2016 to January 2017.

Methodology: Data were collected on 44 anesthesiology trainees completing their training between 2009 and 2015. TSS consisted of entrance test, final-year medical school scores, and interviews. Assessment included written tests, viva voce, and clinical assessment. Non-parametric Spearman rank correlation coefficient was computed to assess the relationship between scores.

Results: Weak correlation was found between TSS and overall assessment scores for first three years of training. Correlation of TSS with clinical component of assessment was weak throughout training, while it was moderately significant with cognitive component of assessment in third and fourth years of training. Correlation between interview scores and cognitive as well as clinical assessment was non-significant. TSS showed weak correlation with success in exit level examination.

Conclusion: Correlation between overall TSS and assessment scores was weak for first three years of training, and becoming moderately positive in later years of training. Cognitive component of TSS had moderately positive correlation with cognitive assessment, but not with clinical performance. Anesthesiology training programmes need to strengthen their selection criteria; and development of structured interviews might prove useful. Future research should focus upon identifying most useful traits in selecting high performers in anesthesiology training.
\end{abstract}

Key Words: Anesthesiology, Selection criteria, Anesthesiology trainees.

\section{INTRODUCTION}

Selection of the right candidates and provision of high quality training for specialty training programmes are of paramount importance to ensure continuous delivery of high-standard healthcare services. Hence, the criteria used for selection of trainees should ideally be capable of predicting their subsequent performance. This predictability of the selection process has been studied in different medical specialties. ${ }^{1}$ The available data has mainly originated from the United States of America (USA), keeping in consideration the selection criteria used specifically in USA. ${ }^{1-8}$ There is limited information available from outside North America. 7,9

The criteria most commonly being used for selection include evidence of medical school performance, reference letters, curriculum vitae, and interviews. ${ }^{9}$ There is a need to assess the predictability of these selection criteria for subsequent performance of the trainees. The authors determined the correlation of

Department of Anaesthesiologyl / Pathology2, The Aga Khan University Hospital, Karachi, Pakistan

Correspondence: Dr. Aliya Ahmed, Department of Anaesthesiology, The Aga Khan University Hospital, Stadium Road, Karachi, Pakistan

E-mail: aliya.ahmed@aku.edu

Received: March 03, 2018; Accepted: September 19, 2018 selection scores with subsequent performance and success in exit-level examination in anesthesiology trainees at a university teaching hospital.

The aim of the study was to identify the selection criteria that are most capable of predicting performance of anesthesiology postgraduate trainees during training in an endeavour to strengthen the selection process.

\section{METHODOLOGY}

Approval was obtained from the Institutional Ethics Review Committee (1647-Anth-ERC). The process for the selection of anesthesiology trainees consisted of a written entrance test to assess basic medical knowledge expected at the end of internship. Shortlisting for interviews was done on the basis of entrance test scores, final year medical school score, and clearance of Part-1 of fellowship examinations conducted by the College of Physicians and Surgeons Pakistan (CPSP). Each selection criterion was categorised from zero to five; and the scores obtained by the candidates were combined to obtain a rank order list. The top $18-20$ applicants from the list were called for interviews. Every candidate was interviewed by two interview panels comprising of three faculty members each. A semistructured interview form was filled by each interviewer independently. The form included questions to assess communication skills, professionalism, leadership 
potential, performance under stress of interview and extra-curricular interests.

Scoring of interview was done on a five-point Likert scale, from poor to exceptional, by each interviewer independently. The interviewers were requested to write a comment about their overall impression of each candidate. A trainee selection score (TSS) was then generated, giving $60 \%$ weightage to the interview scores and $40 \%$ to the shortlisting criteria described above. The final rank order list was formulated according to the TSS. A committee, comprising of department chair, programme director and four faculty members, finalised the selection. The final selection was based mainly on the rank order list, but the committee also scrutinised the interviewers' comments regarding any specific weaknesses or strengths identified for the candidates.

The selected trainees underwent five-year structured training, during which they had two to three monthly rotations in the sub-specialties of anesthesiology. At the end of each rotation, the consultant coordinator for the rotation filled out a continuous assessment form consisting of attributes, including patient care, subject knowledge, procedural skills, interpersonal and communication skills, professionalism, practice-based learning and improvement, and inclination towards research and scholarly activities. Performance in each attribute was marked on a five-point Likert scale, from unsatisfactory to outstanding. The consultant also conducted a 15-20 minutes viva voce pertaining to the subspecialty. The trainees had mid-year and end-of-year assessments, consisting of multiple-choice questions (MCQ), short answer questions (SAQ), and objective structured clinical examination (OSCE). The written test and OSCE comprised $50 \%$ of the final assessment scores. Clinical rotation assessment had a $30 \%$ weightage, while $10 \%$ weightage was given to presentations and $10 \%$ to attendance in academic sessions.

All anesthesiology trainees completing their training from 2009 to 2015 were included in the study, because they had gone through the same selection and assessment processes as detailed above. Trainees selected before the 2009 batch were excluded because the above mentioned selection criteria had not been applied for their selection. This achieved a sample size of 44 as six trainees completed their training each year from 2009 to 2013, while seven completed training in 2014 and seven in 2015.

Data were collected on TSS and in-training assessment scores for each year of training from the department records. A number was assigned to each trainee to ensure anonymity. Trainees' success in FCPS (Fellowship of the College of Physicians and Surgeons Pakistan) Part-2 examination was noted. FCPS Part-2 is the exitlevel examination and aims to ensure that the trainee has achieved knowledge and competencies required for provision of anesthetic management independently.
Statistical analysis was performed using statistical packages for social sciences version 19 (SPSS Inc., Chicago, IL). Mean and standard deviation with 95\% confidence interval were estimated for TSS and performance scores. Frequencies and percentages were computed for success in exit-level examination. Taking the mean selection score of 71 into consideration, trainees were divided into below average and above average groups, to assess if the high-scorers were successful in passing the exit-level examination earlier. Assumptions of Pearson's correlation coefficient and linear regression were not fulfilled; therefore, nonparametric Spearman rank correlation coefficient was computed to assess the direction and strength of relationship between TSS and performance scores. Chisquare test was applied to compare relationships between TSS and success in exit level examination. $\mathrm{P} \leq 0.05$ was considered statistically significant.

\section{RESULTS}

Forty-four trainees were included in the study, 26 (59\%) males and $18(41 \%)$ females. The mean trainee selection score (TSS) was $71.3 \pm 10.6$ (range: $89-53$ ); while mean overall performance score of the trainees was $65.4 \pm 6.2$ (range: 73.6 - 47.1). No significant correlation was seen between TSS and the end-of-year performance for first, second and third years of training $(p=0.48,0.20$ and 0.07 respectively) while significantly positive correlation was observed for fourth $\left(r_{s}=0.361\right.$, $p=0.016)$ and fifth $\left(r_{s}=0.352, p=0.019\right)$ years of training.

The assessment scores were divided into cognitive (knowledge) component $(\mathrm{MCQ}, \mathrm{SAQ}$, viva voce = cognitive component) and clinical component (rotation assessment and OSCE). Trainee selection score was correlated separately with cognitive and clinical components of assessment scores. There was statistically significant correlation between TSS and cognitive component of assessment in third $(p=0.05)$ and fourth $(p=0.001)$ years of training (Table I), while the correlation was insignificant between TSS and clinical component of assessment throughout training (Table I). Cognitive part of TSS (entrance test, MBBS marks,

Table I: Correlation of overall trainee selection scores with cognitive and clinical components of in-training assessment scores in anesthesiology trainees $(\mathrm{N}=44)$.

\begin{tabular}{l|c|c}
\hline \multirow{2}{*}{ Year of training } & \multicolumn{2}{|c}{ Spearmen rank correlation coefficient $(p)$} \\
\cline { 2 - 3 } & \multicolumn{2}{|c}{ TSS $^{*}$ with assessment scores } \\
\cline { 2 - 3 } First year & $0.24(p=0.12)$ & Clinical \\
Second year & $0.21(p=0.16)$ & $0.189(p=0.225)$ \\
Third year & $0.296(p=0.05) \dagger$ & $0.148(p=0.336)$ \\
Fourth year & $0.501(p=0.001) \dagger$ & $0.062(p=0.702)$ \\
Fifth year & $0.11(p=0.49)$ & $0.064(p=0.67)$ \\
\hline
\end{tabular}

${ }^{*} T S S=$ Trainee selection score; $\quad$ tSignificant correlation; $p<0.05$;

Cognitive component of assessment $=M C Q \ddagger+S A Q \S+$ viva voce;

Clinical component of assessment = Rotation assessments + OSCE;

$\neq M C Q=$ Multiple choice question; $\S S A Q=$ Short answer question;

OSCE = Objective structured clinical examination. 
Table II: Correlation of the cognitive component of trainee selection scores with in-training cognitive and clinical assessment and correlation of interview scores with in-training cognitive and clinical assessment in anesthesiology trainees $(\mathrm{N}=44)$.

\begin{tabular}{|c|c|c|c|c|}
\hline \multirow[t]{2}{*}{ Year of training } & \multicolumn{4}{|c|}{ Spearmen rank correlation coefficient $(p)$} \\
\hline & $\begin{array}{l}\text { Cognitive part of TSS* } \\
\text { with cognitive part of } \\
\text { assessment scores }\end{array}$ & $\begin{array}{l}\text { Cognitive part of TSS* } \\
\text { with clinical rotation } \\
\text { assessment }\end{array}$ & $\begin{array}{c}\text { Interview scores with } \\
\text { cognitive part of } \\
\text { assessment scores assessment }\end{array}$ & $\begin{array}{l}\text { Interview scores with } \\
\text { clinical rotation }\end{array}$ \\
\hline First year & $0.344(p=0.011) \dagger$ & $0.335(p=0.028) \dagger$ & $0.142(p=0.358)$ & $0.06(p=0.70)$ \\
\hline Second year & $0.23(p=0.07)$ & $0.287(p=0.059)$ & $0.147(p=0.342)$ & $0.033(p=0.83)$ \\
\hline Third year & $0.235(p=0.06)$ & $0.223(p=0.166)$ & $0.28(p=0.06)$ & $0.038(p=0.814)$ \\
\hline Fourth year & $0.414(p=0.003) \dagger$ & $0.062(p=0.69)$ & $0.433(p=0.003) \dagger$ & $0.131(p=0.39)$ \\
\hline Fifth year & $0.19(p=0.11)$ & $0.193(p=0.21)$ & $0.022(p=0.88)$ & $0.066(p=0.69)$ \\
\hline
\end{tabular}

${ }^{*}$ TSS = Trainee selection score; $\quad$ TSignificant correlation; $p<0.05 ; \quad$ Cognitive component of TSS = Entrance test score, medical school final year marks and FCPS (Fellow of the College of Physicians and Surgeons of Pakistan) Part 1 passed or not; Cognitive component of assessment scores = MCQ + SAQ§ + viva voce; Clinical component of assessment = Rotation assessments + OSCE; $¥ M C Q=$ Multiple choice question; $S A Q=$ Short answer question; OSCE = Objective structured clinical examination.

Table III: Relationship between trainee selection scores and success in exit level examination in anesthesiology trainees.

\begin{tabular}{l|c|c|c|c}
\hline \multirow{2}{*}{$\begin{array}{l}\text { Success in exit level } \\
\text { examination (FCPS* }\end{array}$} & \multicolumn{2}{|c|}{$\begin{array}{c}\text { Trainee selection score } \\
\text { (mean [average] score=71) }\end{array}$} & \multirow{2}{*}{$\begin{array}{c}\text { Total } \\
\mathrm{n}=44\end{array}$} & \multirow{2}{*}{-value } \\
\cline { 2 - 3 } & $\begin{array}{c}\text { Above average } \\
\mathrm{N}(\%)\end{array}$ & $\begin{array}{c}\text { Below average } \\
\mathrm{N}(\%)\end{array}$ & & \\
\hline During training & $9(20.5 \%)$ & $14(31.8 \%)$ & $23(52.3)$ & 0.172 \\
Immediate post training & $10(22.7 \%)$ & $4(9.1 \%)$ & $14(31.8 \%)$ & \\
One year after training & $1(2.3 \%)$ & $3(6.8 \%)$ & $4(9.1 \%)$ & \\
\hline
\end{tabular}

FCPS Part-1 status) correlated significantly with the cognitive assessment scores during first $(p=0.011)$ and fourth years $(p=0.003)$ of training. The interview scores correlated significantly with cognitive assessment only in the fourth year of training $(p=0.003)$, while the correlation was insignificant between interview scores and cognitive as well as clinical assessment for all other years of training (Table II).

Trainee selection scores showed no correlation with success in exit level examinations (Table III). Fourteen $(63.6 \%)$ of the trainees with below average selection scores passed their FCPS Part-2 during the fifth year of their training, while only nine $(41 \%)$ trainees with above average selection scores passed their examinations during training. All other trainees passed FCPS Part-2 within one to two years of finishing their training, irrespective of their selection scores (Table III).

\section{DISCUSSION}

In this study, a weak correlation was found between trainees' selection scores (TSS) and their performance scores during the first three years of training, but the correlation became significantly positive in fourth and fifth years of training. The probable reason for the weak correlation during the first three years of training was that trainees did not have exposure to anesthesiology as undergraduates and needed time to acquire the knowledge and skills required in the practice of anesthesiology. Therefore, even candidates who had achieved higher TSS were not able to obtain good performance scores in the initial years of training. After gaining adequate knowledge and expertise, they started obtaining better performance scores during the final two years of training. The quality of selection criteria to select high performers in anesthesiology has been studied by many researchers in USA.1,2,10-12 Their selection criteria vary considerably; hence, it is difficult to compare them with our results. Metro et al. did not find a statistically significant correlation between their selection criteria and future performance of anesthesiology trainees, ${ }^{1}$ and believed that some personality traits may have a greater-effect on trainee performance. They suggested using questionnaires and personality surveys to assess future performance-related traits.

Trainee selection scores showed weak correlation with clinical performance assessment throughout training, while the correlation was significantly positive with cognitive / knowledge assessment (MCQ, SAQ, viva voce) in the third and fourth years of training in our study. The reason for this may well be that the criteria used for selection mainly consisted of cognitive knowledge and interviews, which were not able to identify the attributes required for good clinical performance. It has been observed earlier that USMLE scores may demonstrate positive correlation with written examination scores during training, without correlating with trainee's clinical performance assessment by faculty. $11,13,14$ Good clinical performance requires multidimensional attributes which may not be predicted by cognitive measures only; which should not be the only criteria for selection of trainees. 15 In this study, correlation of cognitive component of trainee selection scores was moderately significant with both cognitive and clinical assessment during the first year of training. The most likely reason for this finding is that first year trainees are involved in simpler tasks such as preoperative assessment and postoperative care; and are, therefore, able to perform well in cognitionrelated assessments. However, in subsequent years they start specialty rotations where they are required to perform more complex procedures and may struggle to get good scores.

The interview scores showed weak correlation with both cognitive and clinical assessment, except for fourth year of training (Table II). A meta-analysis showed that an interview is a routine part of trainee selection process in most centers. ${ }^{16}$ It may even be the single most important consideration in evaluating the prospective applicants 
for anesthesia specialty training programme. 17 In another study, interview scores were found to have a strong correlation with anesthesia trainees' composite gradepoint average. ${ }^{2}$ Interviews are considered to provide information about applicant's mannerisms and interpersonal skills and provide the opportunity to clarify the missing points in the application form. ${ }^{18}$ Although the interview process is said to be subjective and biased, in the North America, it is often most important factor in determining the final selection. ${ }^{19-21}$ Structured interviews designed to bring out important qualities in an applicant can be created by a psychologist. 22 Multiple mini interviews (MMI) can be used to assess non-cognitive attributes and abilities that contribute to success in a specific specialty. 23,24

In a meta-analysis of studies conducted to evaluate the association between applicants' selection criteria and subsequent performance during training, the strongest positive correlation was found between examinationbased selection criteria and assessments, with minimal correlation between interviews or reference letters and trainee performance. ${ }^{16}$ The results of a study highlight the importance of structured tools for trainee selection process as their selection scores correlated with both cognitive and clinical assessment scores of the trainees. 9

Success in exit level examination (FCPS Part-2) did not show a statistically significant correlation with selection scores in this study. Other researchers have looked into the capability of selection criteria to predict performance in exit level examination. It has been observed that USMLE scores, which are used for resident selection in USA, can predict success in American Board of Anesthesiology exit level examinations, ${ }^{11}$ while interview scores ${ }^{18}$ and faculty assessments ${ }^{25}$ do not correlate with performance in exit level examination. Standardised selection tests like USMLE can predict the ability to learn specialty-specific knowledge and reproduce it in future examinations. ${ }^{11}$ This highlights the importance of standardised medical knowledge examinations for trainee selection to ensure good performance in examinations.

The limitation of this study is that the presented data are retrospective. However, data for selection and evaluation processes are collected in an ongoing prospective manner at the authors' institution and; therefore, the available data are comprehensive and reliable. Other authors have also used retrospective data for similar studies.4,7 Moreover, inclusion of cognitive and clinical assessment scores for each year of the 5-year training programme has led to availability of considerable data for analysis, which has offset the relatively small sample size. Other researchers have used smaller sample size in studies of this nature.1,13,14 More work is required on identifying the criteria that would be most useful in selecting candidates who would perform well during anesthesiology training. The authors plan to work towards identification of attributes important for anesthesiology and introduction of objectivity into the interview process to enable us to identify the most suitable candidates.

\section{CONCLUSION}

The results of this study show that the criteria used for selection of anesthesiology trainees at the authors' institution did not correlate consistently with their subsequent performance. Development of structured tools, including structured interviews, for trainee selection process in anesthesiology would prove useful in selecting the most suitable candidates who would subsequently perform well during training.

\section{REFERENCES}

1. Metro DG, Talarico JF, Patel RM, Wetmore AL. The resident application process and its correlation to future performance as a resident. Anesth Analg 2005; 100:502-5.

2. Warrick SS, Crumrine RS. Predictors of success in an anaesthesiology residency. J Med Educ 1986; 61:591-5.

3. Raman T, Alrabaa RG, Sood A, Maloof P, Benevenia J, Berberian W. Does residency selection criteria predict performance in orthopedic surgery residency? Clin Orthop Relat 2016; 474:908-14.

4. Dirschl DR, Dahners LE, Adams GL, Crouch JH, Wilson FC. Correlating selection criteria with subsequent performance as residents. Clin Orthop Relat Res 2002: 399:265-71.

5. Carmichael KD, Westmoreland JB, Thomas JA, Patterson RM. Relation of residency selection factors to subsequent orthopaedic in-training examination performance. South Med J 2005; 98:528-32.

6. Dirschl DR, Canpion ER, Gilliam K. Resident selection and predictors of performance: Can we be evidence based? Clin Orthop Relat Res 2006; 449:44-9.

7. Hamdy H, Prasad K, Anderson MB, Scherpbier A, Williams R, Zwierstra $\mathrm{R}$, et al. BEME systematic review: Predictive values of measurements obtained in medical schools and future performance in medical practice. Med Teach 2006; 28:103-16.

8. Van Meter M, Williams M, Banuelos R, Carlson P, Schneider JI, Shy $\mathrm{BD}$, et al. Does the national resident match program rank list predict success in emergency medicine residency programs? J Emerg Med 2017; 52:77-82.

9. Oldfield Z, Beasley SW, Smith J, Anthony A, Watt A. Correlation of selection scores with subsequent assessment scores during surgical training. ANZ J Surg 2013; 83:412-16.

10. Swide C, Lasater K, Dilman D. Perceived predictive value of the Medical Student Performance Evaluation (MSPE) in anesthesiology resident selection. J Clin Anesth 2009; 21:38-43.

11. Guffey RC, Rusin K, Chidiac EJ, Marsh HM. The utility of preresidency standardized tests for anaesthesiology resident selection: the place of USMLE scores. Anesth Analg 2011; 112:201-6.

12. Baker JD, Bailey MK, Brahen NH, Conroy JM, Dorman BH, Haynes GR. Selection of anaesthesiology residents. Acad Med 1993; 68:161-3. 
13. Bell JG, Kanellitas I, Shaffer L. Selection of obstetrics and gynaecology residents on the basis of medical school performance. Am J Obstet Gynecol 2002; 186:1091-4.

14. Olawaiye A, Yeh J, Withiam-Leitch M. Resident selection process and prediction of clinical performance in an obstetrics and gynaecology programme. Teach Learn Med 2006; 18:310-5.

15. Berner ES, Brooks CM, Erdmann JB. Use of the USMLE to select residents. Acad Med 1993; 68:753-9.

16. Kenny S, Mclnnes M, Singh V. Associations between residency selection strategies and doctor performance: a meta-analysis. Med Educ 2013; 47:790-800.

17. Spielman FJ, Bowe EA. A survey of anesthesiology chairmen regarding resident selection criteria. Anesthesiology 1982; 57: A453.

18. Crane JT, Ferraro CM. Selection criteria for emergency medicine residency applicants. Acad Emerg Med 2000; 7:54-60.

19. Makdisi G, Takeuchi T, Rodriguez J, Rucinski J, Wise L. How we select our residents - A survey of selection criteria in general surgery residents. J Surg Educ 2011; 68:67-72.
20. Wagoner NE, Suriano R. Program directors' responses to a survey on variables used to select residents in a time of change. Acad Med 1999; 74:51-8.

21. Smilen S, Funai E, Bianco A. Residency selection: should interviewers be given applicants' board scores? Am J Obstet Gynecol 2011; 184:508-13.

22. Verchere $C$. Choosing the right resident. BCMJ 2011; 53:63-4.

23. Stephenson-Famy A, Houmard BS, Oberoi S, Manyak A, Chiang S, Kim S. Use of the interview in resident candidate selection: a review of the literature. J Grad Med Educ 2015; 7:539-48.

24. Hopson LR, Burkhardt JC, Stansfield RB, Vohra T, TurnerLawrence D, Losman ED. The multiple mini-interview for emergency medicine resident selection. J Emerg Med 2014; 46:537-43.

25. Thordarson DB, Ebramzadeh E, Sangiorgio SN, Schnall SB, Patzakis MJ. Resident selection: how we are doing and why? Clin Orthop Relat Res 2007; 459:255-9. 